\title{
Life Satisfaction and Wellness in Chinese College Students 本港大學生的生活滿足感與身心康盛
}

\author{
Jofy PANG \\ Department of Physical Education, \\ Hong Kong Baptist University, HONGKONG
}

彭秀蓮

香港浸會大學體育學系

\begin{abstract}
This study aims to identify the relationship between life satisfaction and wellness in Chinese college students. A survey design was used. Based on the analysis of 338 sets of data, a significant and positive relationship between life satisfaction and wellness was established. In addition, students were found to be least satisfied with their living environment and most satisfied with their relationship with friends. Of the five dimensions of wellness, students scored the lowest in the physical dimension.

\section{摘 要}

本文目的是探討本港大學生的生活滿足感與身心康盛的關係。透過分析收回的338份問卷，結果顯示同學之生活滿足感與其 身心康盛有顯著的正面關係，而本港的大學生對朋輩關係之滿意程度最高，對生活環境之滿意程度則最低。在五項身心康盛的自 我評估範疇中，本港大學生在身體康盛的得分最低。
\end{abstract}

\section{Introduction}

Half a century ago, the word "wellness" was almost unheard of. Today, wellness is fast becoming a household word and programs to aid individuals achieve high level wellness are plethoric. However, despite our increasing interest in wellness, related empirical research is sparse. Therefore, the main purpose of this study was to generate a wellness profile from a sample of college students with the hope that the findings could be used to inform student affairs management units of required services for this population. In addition, the study aimed to contribute to the wellness literature by exploring the influence of life satisfaction on wellness.

\section{Literature Review}

\section{Wellness}

Wellness is multidimensional (Witmer \& Sweeney, 1992). Corbin and Pangrazi (2001) reviewed literature related to wellness and pointed out that wellness models can have two, five, or seven dimensions. However, they argued that the basics of personal wellness are the physical, social, intellectual, emotional, and spiritual dimensions. Other dimensions, such as vocational and environmental, might be characteristics of the environment that influence an individual's wellness. They are also of the view that once the measurement of wellness could be made, factors affecting wellness must be studied. 
Search of wellness related literature showed a positive lean towards two areas, namely the effectiveness of planned intervention on wellness and the impact of specific behaviors, such as smoking or exercise, on wellness (cf. Harvey, Fleming, \& Patterson, 2002; Steptoe $\&$ Butler, 1996). Typically, the population samples most involved in wellness studies are adults, seniors, or persons with specific health problems. Research involving college students is particularly sparse. Addressing this problem, Granello (1999) initiated a study to examine students' wellness as a function of social support network and empathic ability. His results indicated that none of those variables were significant predictors of wellness. To explain the disparity between his findings with those in the literature, Granello suggested that chronological age, and hence developmental stage, of his sample could be the contributing factor. He further asserted that as compared to samples used in previous studies, namely children or older adults, his college sample, might have perceived the importance of empathy and social support differently.

While Granello (1999) utilized wellness as the dependent variable, Hermon and Hazler (1999) made components of wellness the independent variable. Their interest was on establishing relationships between the five components of wellness and the trait and state measures of psychological well-being. Results of their study indicated that spirituality, work/recreation/leisure, friendship, love, and self-regulation were all significantly related to the trait and state of psychological well-being. In particular, self-regulation and work/recreation/leisure were the better predictors.

In a more recent study, Hermon and Davis (2004) studied the impact of age and maturity on sub-components of a wellness model. Specifically, they compared nontraditional students (students at a mature age of 24 to 51) with traditional students (students at the age of 17 to 23) on 16 wellness measures and found more similarities than differences between both groups of students. They concluded that in college students, age is not a significant differentiator of wellness levels. This finding was contradictory to an earlier study by Hybertson, Hulme, Smith, and Holton (1992) who found that age interacted with environmental factors to influence wellness. Older students reported that poorer social support systems and poorer social relationships had a negative effect on their wellness.
The preceding review showed that there is relatively little research on antecedences of college student wellness. Furthermore, there is a lack of consensus on whether age and maturity influence wellness.

\section{Life Satisfaction}

Life satisfaction, defined as a cognitive evaluation of the quality of a person's overall life or with specific aspects of life, such as family, friends, and community (Pavot, Diener, Colvin, \& Sandvik, 1991). This construct was selected as an interest variable for this study for two reasons. First, early research on life satisfaction was mostly focused on profiling adults but has now progressed to include a wider population such as adolescents and college students (Diener, Suh, Oishi, Lucas, \& Smith, 1999). To the extent that new information on this construct would contribute to existing literature, the choice is appropriate.

Second, past research on life satisfaction often treated the construct as an outcome variable, and the impact of individual differences, such as gender (Cheng \& Chan, 2006), risky health behaviors (Valois, Zullig, Huebner \& Drane, 2004), and personality (Lyubomirsky, Tkach, \& DiMatteo, 2006) on life satisfaction is a key focus of research. By comparison, little effort has been spent on examining consequences of life satisfaction (Gilman \& Huebner, 2006). Therefore, another contribution of this study is to begin a trend of research in which life satisfaction is used as a predictor variable.

\section{Method}

\section{Participants}

We extended invitation to 380 first-year full-time undergraduate students enrolled in a 15-week required subject on health and physical activity to take part in the study. From the completed returns, 335 valid questionnaires were used for data processing. This constituted a valid return rate of over $88 \%$. The number of male students was 146 whereas the number of female students was 189 . Their age ranged from 18 to 29. 


\section{Measures}

A questionnaire comprising of three parts was used for data collection. The first part comprised of demographic questions on gender and age whereas the second part seeks responses to satisfaction in the five areas of Family, Friendship, School, Living Environment, and Self. Items for this part of the questionnaire were derived from a previously developed scale to assess students' life satisfaction (Huebner, 1991). Sample items for each area include 'members of my family talk nicely to me', 'my friends treat me well', 'I enjoy school activities', 'I like my neighborhood', and 'I think I am good looking'. All items are scored on a 6-point scale (1-point for strongly disagree and a 6-point for strongly agree). The third part of the questionnaire seeks for selfevaluation of wellness in the Social, Physical, Emotional, Intellectual, and Spiritual dimensions. Items for this part of the questionnaire were based on a scale previously used by the investigators. Sample items included 'I am able to communicate and get along with a variety of people', 'I avoid tobacco products', 'I am able to laugh at life and myself', 'I am interested in learning new things', and 'life is meaningful and I feel a purpose in life'. All items in this part are scored on a 3-point scale (2-point for almost always and 0-point for very seldom).

\section{Procedures}

Data was obtained via a self-reporting questionnaire. They were distributed and collected in class by the investigators during the first and second week of the semester. The purpose of the study, voluntary participation, and anonymous return was made known to all students prior to data collection.

\section{Data Analysis}

Structural equation modeling was the main form of analysis used in this study. To proceed with this form of analysis, a hypothesized model on the relationship between life satisfaction and wellness was constructed for estimation. The model contained two latent constructs, namely, life satisfaction and wellness. For the construct of life satisfaction, five factors (family, friends, school, living environment, and self) served as exogenous variables while for the construct of wellness, another five factors (social, physical, emotional, intellectual, and spiritual) served as its exogenous variables.
To assess the tenability of the hypothesized model, multiple goodness-of-fit indices, including the TuckerLewis Index (NNFI), ratio of $x^{2}$ to degree of freedom $\left(x^{2}\right.$ / df), root-mean-square error of approximation (RMSEA), and comparative fit index (CFI) were adopted as criterion. Ideally, the value of the NNFI and CFI indices need to reach .90 before the model could be accepted as having a good fit (Hu \& Bentler, 1999) whereas the $\left(x^{2} / \mathrm{df}\right)$ need to range between 2 to 5 (Kline, 1998) and the RMSEA need to be less than .05 (Hu \& Bentler, 1999). However, a model could be considered tenable even when the indices are slightly off if there is sufficient theoretical underpinning to substantiate the claims, especially when the study is exploratory in nature (Kline, 1998).

\section{Results}

The means and standard deviations of the five life satisfaction factors and five wellness dimensions are presented in Table 1. Correlation coefficients among the life satisfaction factors and wellness dimensions are presented in Table 2.

Table 1. Means and Standard Deviations of Life Satisfaction Areas and Wellness Components.

\begin{tabular}{|c|c|c|}
\hline Components & $\mathrm{M}$ & SD \\
\hline \multicolumn{3}{|l|}{ Leisure Satisfaction: } \\
\hline Family & 4.24 & .90 \\
\hline Friends & 4.83 & .61 \\
\hline School & 4.16 & .62 \\
\hline Living Environment & 3.96 & .71 \\
\hline Self & 4.15 & .61 \\
\hline \multicolumn{3}{|l|}{ Wellness: } \\
\hline Social & 13.88 & 2.50 \\
\hline Physical & 12.54 & 2.57 \\
\hline Emotional & 14.48 & 2.84 \\
\hline Intellectual & 14.25 & 2.64 \\
\hline Spiritual & 13.47 & 2.90 \\
\hline
\end{tabular}


Table 2. Correlation Coefficients among Life Satisfaction Areas and Wellness Dimensions.

$\begin{array}{llllllll}\text { Family } & \text { Friends } & \text { School } & \begin{array}{l}\text { Living } \\ \text { Environment }\end{array} & \text { Self } & \text { Social } & \text { Physical } & \text { Emotional Intellectual Spiritual }\end{array}$

\begin{tabular}{llllllllll}
\hline Friends & .34 & & & & & & & & \\
School & .28 & .35 & & & & & & & \\
Living Environment & .46 & .34 & .31 & & & & & & \\
Self & .36 & .37 & .44 & .38 & & & & & \\
Social & .18 & .21 & .25 & .30 & .46 & & & & \\
Physical & .13 & .06 & .11 & .20 & .27 & .38 & & & \\
Emotional & .22 & .27 & .28 & .28 & .55 & .56 & .38 & & \\
Intellectual & .04 & .06 & .22 & .09 & .22 & .37 & .30 & .42 & .54 \\
Spiritual & .11 & .12 & .18 & .17 & .35 & .45 & .36 & .56 & \\
\hline
\end{tabular}

Using means and standard deviations as reference, the students were found to be most satisfied in the area of Friendship $(\mathrm{M}=4.83, \mathrm{SD}=.61)$ and least satisfied in the area of Living Environment $(\mathrm{M}=3.96, \mathrm{SD}=.71)$. Of the five dimensions of wellness, students perceived themselves to be weakest in the Physical dimension (M $=12.54, \mathrm{SD}=2.57)$ and strongest in the Emotional dimension $(\mathrm{M}=14.48, \mathrm{SD}=2.84)$.

In order to assess whether the difference between the mean of Friendship and the mean of Living Environment was sufficiently large enough to warrant acceptance of a rank order distinction, a paired-sample t-test was performed on the data. In applying this procedure, the two satisfaction factors (Friends and Living Environment) were treated as two dependent variables so that upon obtaining a statistically significant t-ratio at the pre-determined alpha level of .05 , the means of the two variables would be considered significantly different. A similar process was applied to data of the Physical and Emotional dimensions.

Results of the paired t-tests suggested that the differences in mean scores between Friends and Living Environment and between Physical and Emotional were statistically significant (Friends and Living Environment: $\mathrm{t}$ $=20.56, \mathrm{p}<.05$; Physical and Emotional: $\mathrm{t}=11.77, \mathrm{p}$ $<.05)$. This indicated that the treatment of the variables as having a distinct rank order is justified.

Examination of the goodness-of-fit indices selected for determining the fit between hypothesized model and data suggested that, except for the RMSEA, all indices reached the critical regions and thus warrant the model to be tenable (NNFI $=.96, \mathrm{CFI}=.97$, and $\mathrm{x}^{2} / \mathrm{df}=2.26$ ). Although the RMSEA was slightly over the critical region of .05 (RMSEA = .06), we feel that it is sufficiently close enough for acceptance. The accepted model and standardized path coefficients are presented in Figure 1.

Figure 1. Model showing Standardized Path Coefficients

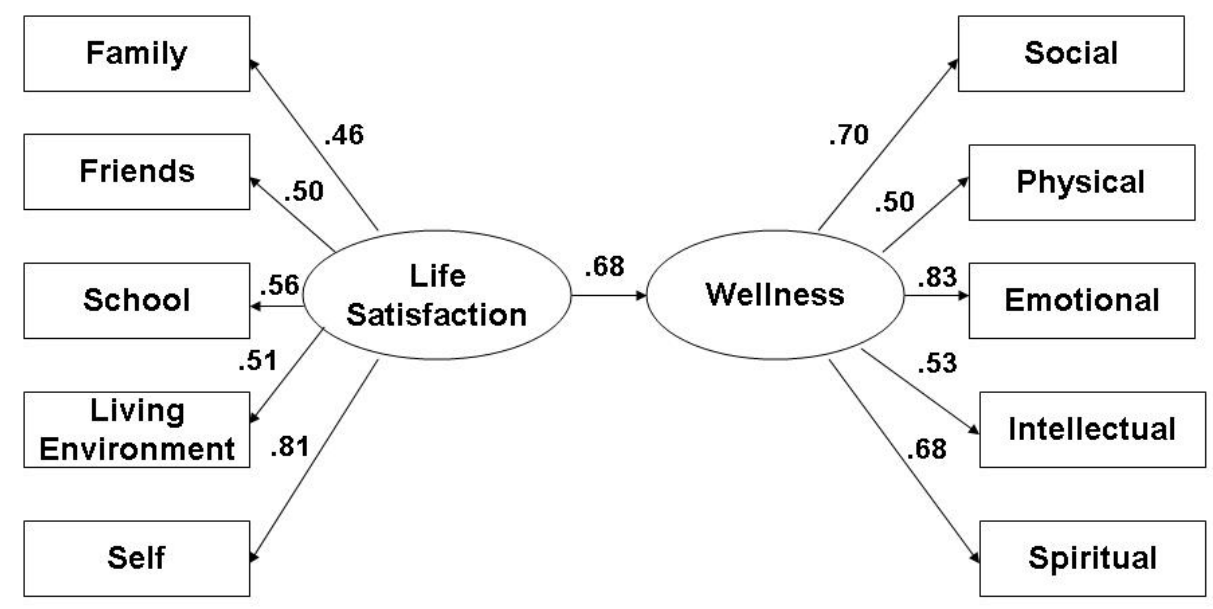




\section{Discussions}

The purpose of the study was to assess whether life satisfaction could be established as an influential correlate of wellness. By fitting a hypothesized model to data collected from a group of Chinese college students, the positive relationship between life satisfaction and wellness was confirmed $(\mathrm{r}=.68, \mathrm{p}<.05)$. In addition, in contrast to previous research on life satisfaction that treated the construct as an outcome variable, we set out to assess whether life satisfaction could serve as a precursor to another important construct, which, in this study, was wellness. To the extent that the goodness-of-fit indices associated with our model testing reached critical regions, and that the model contains a directional path from life satisfaction to wellness, our argument on the usefulness of life satisfaction as a predictor variable is substantiated.

Of the five areas of life satisfaction, students were found to be most satisfied with their present status of friendship and least with their living environment. Students' higher scores in friendship showed that they had built a satisfactory support system among their friends. The result is consistent with the developmental stage of college students. Individuals at the college stage is said to have gained autonomy from their family but friends and peers still play an important role (Berk, 2004). If influence from friends and peers are still dominant among this group, it is advisable for student affairs management units to maintain a strong peer counseling training program and entrust peer assistance to help the university students when needs arise.

Hong Kong is a densely populated city and living conditions are crowded, so it is common to have four to five family members sharing a flat of no more than a few hundred square feet. Given the prevalence of this type of living condition, the finding of students being least satisfied with their living environment did not came as a surprise. Places in university hostels are tight and despite the fact that universities receive grants and donations, spending these funds on hostels has not been the universities' priority. Helping students to source for affordable off-campus quarters is a service available in many overseas universities, perhaps Hong Kong's student affairs management units could, likewise, lend some assistance to their students.
Wellness, in this study, is comprised of five dimensions. Students perceived that they were weakest in the Physical dimension and strongest in the Emotional dimension. Although it is not uncommon for individuals to experience strength variations in different domains at any given point in time, the mean score of 12.54 for the Physical dimension is considered as having "room for improvement" (cf. Health Promotion Office of Illinois State University, n.d.). One possible explanation for the low scores in the Physical dimension is the sedentary life style of the university students in Hong Kong. It is consistent with the observation of Leung (1998) who pointed out that most of the youth in Hong Kong were inactive and consumed a lot of animal food in their diet. This lifestyle would put them at risk of chronic diseases as they mature into middle adulthood. Many overseas universities have wellness centers within their student affairs management units. These centers take on the responsibility of providing health talks, health checks, and wellness programs to students. Currently, there does not seem to be a designated staff within any student affairs management units in Hong Kong that take on the specific role of wellness promotion to students. Isolated counseling programs and education talks cannot replace a comprehensive wellness program where each student's well-being is monitored and tracked. Although wellness is often considered a personal strife, to have a proactive system in place would ensure that students can get the support towards achieving wellness.

\section{Conclusion}

In conclusion, life satisfaction was found to be an important contributor to wellness in Chinese college students. As this study only involved a convenient sample, caution must be applied in generalization to similar sample groups in Hong Kong. Perhaps future research could include a more diversify sample group and assess whether the phenomenon found in this study could be replicated. Although there are limitations to this study, it did represent a successful attempt in producing a wellness profile on this population which did not exist prior to this effort, and the data gathered from this study could indeed be profitable used as a benchmark value for future research. 


\section{References}

Berk, L.E. (2004). Development through the lifespan $\left(3^{\text {rd }} e d\right)$. Boston, MA: Allyn and Bacon.

Cheng, S.T., \& Chan, A.C.M. (2006). Relationship with others and life satisfaction in later life: do gender and widowhood make a difference? The Journal of Gerontology, 61B, 46-53.

Corbin,C.B., \& Pangrazi, R.P. (2001). Toward a uniform definition of wellness: a commentary. Research Digest, 3, $1-8$.

Diener, E., Suh, E., Oishi, S., Lucas, R.E., \& Smith, H.L. (1999). Subjective well-being: Three decades of progress. Psychological Bulletin, 125, 276-302.

Gilman, R., \& Huebner, E.S. (2006). Characteristics of adolescents who report very high life saisfaction. Journal of Youth and Adolescence, 35, 311-319.

Granello, P.F. (1999). College students' wellness as a function of social support and empathic ability. Journal of College Counseling, 2, 110-120.

Harvey, H.D., Fleming, P., \& Patterson, M. (2002). Ethical dilemmas and human rights considerations arising from the evaluation of a smoking policy in a health promoting setting. Journal of Environmental Health Research, 12, 269-275.

Health Promotion Office of Illinois State University (n.d.). Wellness questionnaire. Retrieved from http://www. wellness.ilstu.edu/emotional/.

Hermon,D.A., \& Hazler, R.J. (1999). Adherence to a wellness model and perceptions of psychological wellbeing. Journal of Counseling and Development, 77, 339-343.

Hermon, D.A., \& Davis, G.A. (2004). College student wellness: a comparison between traditional and nontraditional age students. Journal of College Counseling, 7, 32-39.

Hu, L., \& Bentler, P.M. (1999). Cutoff criteria for fit indices in covariance structure analysis: Conventional criteria versus new alternatives. Structural Equation Modeling, 6, 1-53.
Huebner, E.S. (1991). Initial development of the Students' Life Satisfaction Scale. School Psychology International, 12, 231-240.

Hybertson, D., Hulme, E., Smith, W.A., \& Holton, M.A. (1992). Wellness in non-traditional-age students. Journal of College Student Development, 33, 50-55.

Kline, R.B. (1998). Principles and practice of structural equation modeling. New York: Guilford Press.

Leung, S.F. (1998). The Implications of Population Health Conditions to Services for Young People. Journal of Youth Studies. Retrieved from http://www.hkfyg. org.hk/yrc/chinese/yr-jys 1-1-abs.html

Lyubomirsky, S., Tkach, C., \& DiMatteo, M.R. (2006). What are the differences between happiness and selfesteem. Social Indicators Research, 78, 363-404.

Pavot, W.E., Diener, E., Colvin, C.R., \& Sandvik, E. (1991). Further validation of the satisfaction with Life Scale: evidence for the cross-method convergence of well being measures. Personality Assessment, 57, 149-161.

Steptoe, A., \& Butler, N. (1996). Sports participation and emotional wellbeing in adolescents. Lancet, 347, 1789-1792.

Valois, R.F., Zullig,K.J., Huebner, E.S., \& Drane, J.W. (2004). Life satisfaction and suicide among high school adolescents. Social Indicators Research, 66, 81-105.

Witmer, M.J., \& Sweeney, T.J. (1992). Aholistic model for wellness and prevention over the life span. Journal of Counseling and Development, 71, 140-148.

Zullig, K.J., Huebner, S., Gilman, R., Patton, J.M., \& Murray, K.A. (2005). Validation of the brief multidimensional students' life satisfaction scale among college students. American Journal of Health Behavior, 29, 206-214.

\section{Correspondence:}

Jofy Pang

Department of Physical Education

Hong Kong Baptist University

Shek Mun Campus

8 On Muk Road, Shek Mun, Shatin, N.T.

Email: jpang@hkbu.edu.hk 